\title{
PROFILE OF HOSPITALISED CHILDREN WITH ACUTE POISONING IN A TERTIARY CARE HOSPITAL
}

\author{
R. Bhavanishankar ${ }^{1}$, P. Ramu², P. Rakesh ${ }^{3}$
}

${ }_{1}^{1}$ Associate Professor, Department of Paediatrics, Sri Venkateswara Medical College, Tirupati. ${ }^{2}$ Associate Professor, Department of Paediatrics, Government Medical College, Ananthapuramu. 3 Postgraduate Student, Department of Paediatrics, Andhra Medical College, Visakhapatnam.

\section{ABSTRACT}

\section{BACKGROUND}

Acute poisoning in children is one of the most common medical emergencies encountered in paediatric clinical practice with preventable morbidity and mortality and is mostly accidental in nature, especially in children and adolescents, but rarely it could be suicidal/voluntary in adolescents. Hence, paediatrician must have a thorough knowledge regarding the range of possible poisonous substances, high risk groups, environmental factors that add further risk of acute poisoning in children and also treatment of acute poisoning. Further, a paediatrician must play an important role to prevent poisoning in children by providing anticipatory guidance to parents.

The aim of this observational study is to find out clinical and epidemiological profile of acute poisoning in hospitalised children.

\section{MATERIALS AND METHODS}

A total of 117 children aged below 12 years admitted between May 2015 to April 2017 in Paediatric Department of King George Hospital, a Tertiary Care Hospital at Visakhapatnam with a diagnosis of acute poisoning were included in the study.

\section{RESULTS}

During the study period, one hundred and seventeen (117) children aged below 12 years were admitted with history of acute poisoning. In this study, Boys: Girls ratio was 1:1.12 and the most common age group affected was between 1-5 years. Higher number of cases were reported from rural and urban slums (47.9\%\& 40.2\% respectively). In our study, majority (73\%) belonged to lower socioeconomic status. Kerosene was the most common poisoning agent $(29 \%)$ that was implicated in hospitalised children with acute poisoning in our study. Vomiting, altered sensorium, unconsciousness and respiratory distress were the common symptoms or signs of presentation.

\section{CONCLUSION}

We conclude that in our area kerosene poisoning (accidental ingestion) is the common form of acute poisoning.

\section{KEYWORDS}

Acute Poisoning, Accidental Poisoning, Hospitalised Children, Kerosene Ingestion.

HOW TO CITE THIS ARTICLE: Bhavanishankar R, Ramu P, Rakesh P. Profile of hospitalised children with acute poisoning in a tertiary care hospital. J. Evolution Med. Dent. Sci. 2018;7(01):71-75, DOI: 10.14260/jemds/2018/17

\section{BACKGROUND}

Accidental poisoning represents one of the most common medical emergencies encountered by young children and adolescents. ${ }^{1}$ The paediatric emergency toxicology is unique because of its natural division into two distinct components. Young children aged 1 to 5 years who innocently ingested small amounts of a single substance constitute the first group. ${ }^{1}$ Those at higher risk include male gender, hyperactivity and increased finger mouth activity or pica. Environmental factors like new baby in house, marital disharmony among parents, illness and economic crisis add further risk. Paediatricians can play an important role to prevent poisoning in these children by providing anticipatory guidance. ${ }^{1,2}$ The second group of children which is more prone to poisoning, includes adolescents who purposefully ingests

'Financial or Other Competing Interest': None.

Submission 17-11-2017, Peer Review 12-12-2017,

Acceptance 19-12-2017, Published 01-01-2018.

Corresponding Author:

Dr. P. Ramu,

Raja Sagi Residency, FF3, D. NO. 14-1-122/13,

Nowroji Road, Maharanipeta,

Visakhapatnam-530002

Andhra Pradesh.

E-mail: drpramu73@gmail.com

DOI: $10.14260 /$ jemds/2018/17 larger amounts of one or more substances because of emotional or psychiatric distress. Children between these groups are less commonly poisoned.1,2

The exact incidence and prevalence of acute poisoning is not known in India but it is quite common and unreported problem in children.1,2 Hence, we studied the profile of hospitalised children with acute poisoning in terms of clinical and epidemiological data.

\section{MATERIALS AND METHODS}

This cross-sectional study was conducted in the Department of Paediatrics, King George Hospital, Visakhapatnam for 2 years i.e. between May 2015 to April 2017 where in a total of 117 hospitalised children aged below 12 years of age with a diagnosis of acute poisoning were included. Suspected, doubtful cases and cases left against medical advice early in the course of treatment were excluded from the present study. Diagnosis of acute poisoning was made basing on history and physical examination findings. A detailed clinical history was taken with reference to gender, age, socioeconomic status as per modified B. G. Prasad's classification (revised 2014), demography, nature of poisoning, presenting symptoms and signs. Profile of patients with acute poisoning were analysed. 


\section{RESULTS}

In the present study, one hundred and seventeen (117) hospitalised children aged below 12 years with a diagnosis of acute poisoning were included. In this study, Boys: Girls ratio was 1:1.12 (Table - 1). The commonest age group affected was between 1-5 years (31 Boys and 21 Girls), total 52 (44.4\%) (Table-2). Children from rural area dominated the present study population accounting for $47.9 \%$ (56 out of 117) (Table - 3). In our study, we had 86 out of 117 (73.5\%) children from lower socioeconomic status and 9 out of 117 $(7.7 \%)$ children from upper class (Table - 4). Kerosene oil was the most common poisonous agent (29.1\%) implicated in acute poisoning among the hospitalised children in our study (Table - 5). Various clinical symptoms and signs among our study population was depicted in Table -6 , of which vomiting and altered sensorium and/or unconsciousness and respiratory distress dominated the list.

\begin{tabular}{|c|c|c|}
\hline Gender & Number of Cases & $\mathbf{\%}$ \\
\hline Boys & 55 & 47 \\
\hline Girls & 62 & 53 \\
\hline Total & $\mathbf{1 1 7}$ & $\mathbf{1 0 0}$ \\
\hline $\begin{array}{c}\text { Table 1. Distribution of Hospitalised Children with Acute } \\
\text { Poisoning According to Gender in the Present Study } \\
(\mathrm{n}=\mathbf{1 1 7})\end{array}$ \\
\hline
\end{tabular}

\begin{tabular}{|c|c|c|c|c|c|}
\hline $\begin{array}{c}\text { Age in } \\
\text { Years }\end{array}$ & $\begin{array}{c}\text { Boys } \\
\text { Number } \\
\text { Of Cases }\end{array}$ & \% & $\begin{array}{c}\text { Girls } \\
\text { Number } \\
\text { of Cases }\end{array}$ & $\mathbf{\%}$ & Total (\%) \\
\hline$<1$ & 1 & 0.9 & 0 & 0 & $1(0.9)$ \\
\hline $1-5$ & 31 & 26.4 & 21 & 18 & $52(44.4)$ \\
\hline $6-10$ & 14 & 12 & 22 & 18.8 & $36(30.8)$ \\
\hline $10-12$ & 9 & 7.7 & 19 & 16.2 & $28(23.9)$ \\
\hline Total & $\mathbf{5 5}$ & $\mathbf{4 7 \%}$ & $\mathbf{6 2}$ & $\mathbf{5 3 \%}$ & $\mathbf{1 1 7 ( 1 0 0 )}$ \\
\hline
\end{tabular}

Table 2: Distribution of Hospitalised Children with Acute Poisoning According to Age in the Present Study (n=117)

\begin{tabular}{|c|c|c|}
\hline Living Area & Number of Cases & $\mathbf{\%}$ \\
\hline Rural & 56 & $47.9 \%$ \\
\hline Urban slum & 47 & $40.2 \%$ \\
\hline Urban & 14 & $11.9 \%$ \\
\hline TOTAL & $\mathbf{1 1 7}$ & $\mathbf{1 0 0 \%}$ \\
\hline $\begin{array}{l}\text { Table 3: Distribution of Hospitalised Children with Acute } \\
\text { Poisoning According to Living area in the Present Study } \\
\text { (n=117) }\end{array}$ \\
\hline
\end{tabular}

\begin{tabular}{|c|c|c|}
\hline Socioeconomic Status & Number of Cases & $\mathbf{\%}$ \\
\hline Upper class & 09 & 7.7 \\
\hline Middle class & 22 & 18.8 \\
\hline Lower class & 86 & 73.5 \\
\hline TOTAL & $\mathbf{1 1 7}$ & $\mathbf{1 0 0}$ \\
\hline
\end{tabular}

Table 4. Distribution of Hospitalised Children with Acute Poisoning According to Socioeconomic Status of these Families in the Present Study (n=117)

\begin{tabular}{|c|c|c|}
\hline Poisonous Agent & Number of Cases & \% \\
\hline Kerosene (hydrocarbon) & 34 & 29.1 \\
\hline $\begin{array}{c}\text { Pyrethroids/Mosquito } \\
\text { repellents }\end{array}$ & 14 & 12 \\
\hline Drugs (Therapeutic) & 12 & 10.3 \\
\hline $\begin{array}{c}\text { Organophosphorous } \\
\text { compounds }\end{array}$ & 8 & 6.8 \\
\hline Pesticides/Rat killer & 2 & 1.7 \\
\hline Detergent/soap/surf & 9 & 7.7 \\
\hline Room/Floor cleaner & 7 & 5.9 \\
\hline
\end{tabular}

\begin{tabular}{|c|c|c|}
\hline Unknown & 19 & 16.2 \\
\hline Miscellaneous & 12 & 10.3 \\
\hline TOTAL & $\mathbf{1 1 7}$ & $\mathbf{1 0 0}$ \\
\hline
\end{tabular}

Table 5. Distribution of Poisonous Agents Implicated in Hospitalised Children with Acute Poisoning in the Present Study (n=117) Explanations: Unknown\# - when the exact chemical nature of the poisonous substance is not known. Miscellaneous\#\# - includes Mercury ( $n=2)$, Datura fruits $(n=4)$,lens cleaner( $(n=3)$, Dettol liquid $(n=1)$, Lizard in food $(n=2)$, total-12.

\begin{tabular}{|c|c|c|}
\hline Symptoms/Signs & Number of Cases & $\mathbf{\%}$ \\
\hline Vomiting & 98 & 83.8 \\
\hline $\begin{array}{c}\text { Altered sensorium \& } \\
\text { unconsciousness }\end{array}$ & 62 & 52.9 \\
\hline Respiratory distress & 31 & 26.5 \\
\hline Convulsions & 9 & 7.7 \\
\hline Fever & 22 & 18.8 \\
\hline Headache & 15 & 12.8 \\
\hline Diarrhoea & 9 & 7.7 \\
\hline Oliguria/Anuria & 4 & 3.4 \\
\hline Irritability/Restlessness & 16 & 13.7 \\
\hline Drooling of saliva & 12 & 10.3 \\
\hline Asymptomatic & 12 & 10.3 \\
\hline Abdominal pain & 19 & 16.2 \\
\hline Bradycardia & 12 & 10.3 \\
\hline Tachycardia & 8 & 6.8 \\
\hline Miosis & 8 & 6.8 \\
\hline Characteristic smell & 28 & 23.9 \\
\hline Table 6. Clinical symptoms & (m) & \\
\hline
\end{tabular}

Table 6. Clinical Symptoms (modes) of Presentation of Acute Poisoning in Children in the Present Study (n=117)

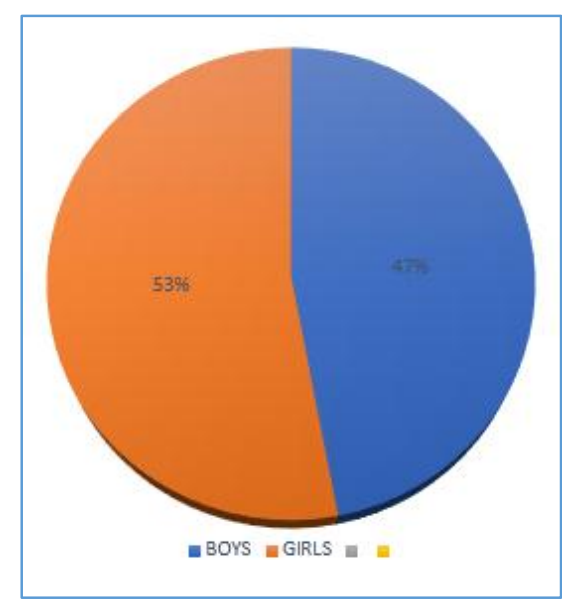

Figure 1. Pie Diagram showing Distribution of Hospitalised Children with Acute Poisoning According to Gender in the Present Study $(n=117)$

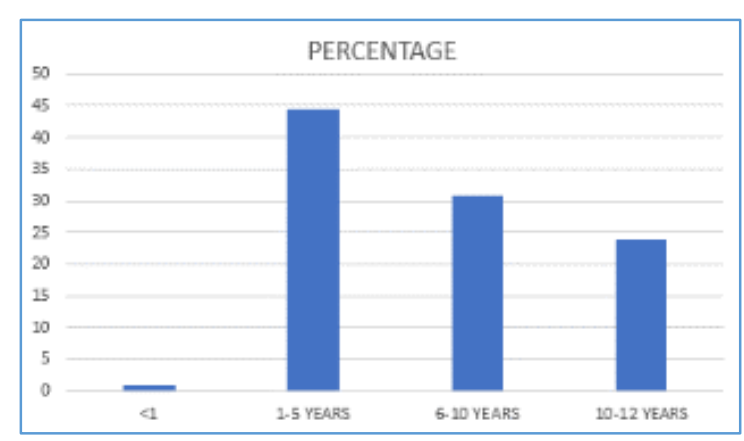

Figure 2. Bar Diagram showing Distribution of Hospitalised Children with Acute Poisoning According to Age in the Present Study ( $n=117)$ 


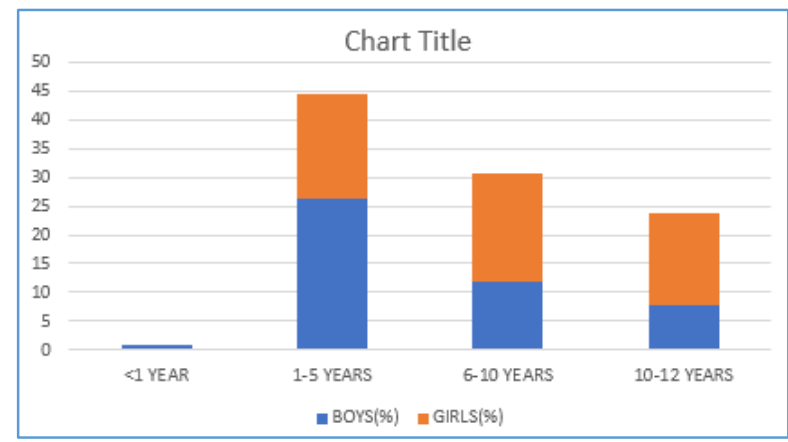

Figure 3. Bar diagram showing Distribution of Hospitalised Children with Acute Poisoning According to Gender in the Present Study (n=117)

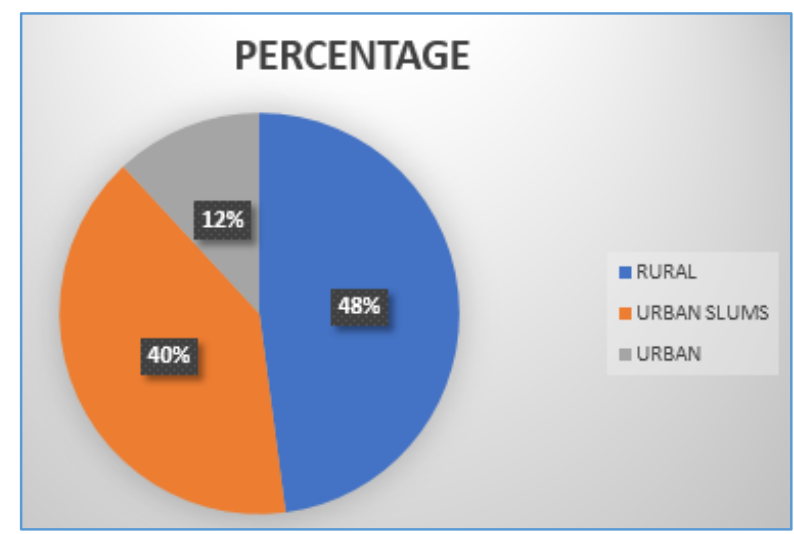

Figure 4. Pie Diagram showing Distribution of Hospitalised Children with Acute Poisoning According to Living Area in the Present Study (n=117)

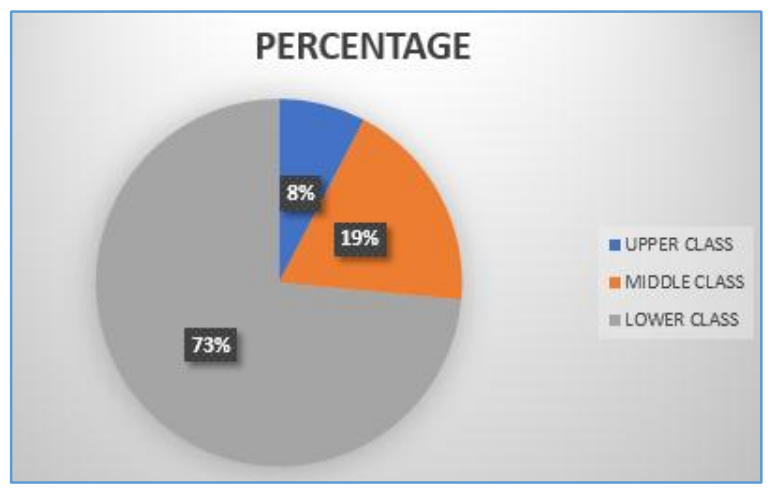

Figure 5. Pie Diagram showing Distribution of Hospitalised Children with Acute Poisoning According to Socioeconomic Status of these Families in the Present Study (n=117)

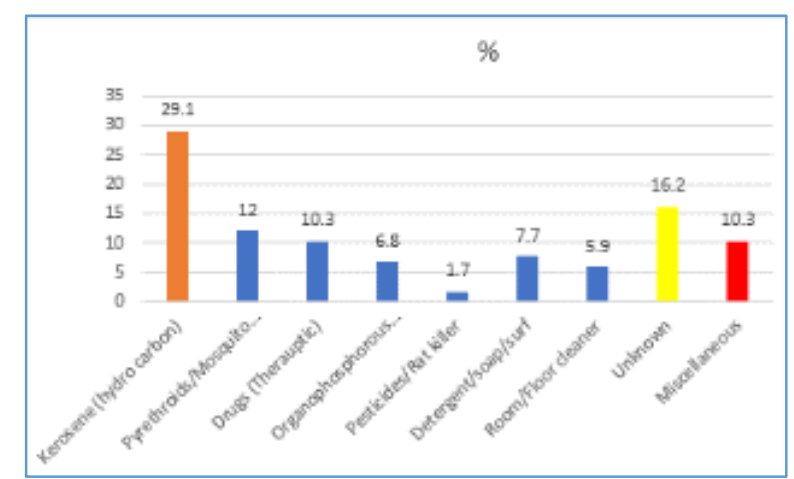

Figure 6. Bar diagram Distribution of Poisonous Agents Implicated in Hospitalised Children with Acute Poisoning in the Present Study (n=117)

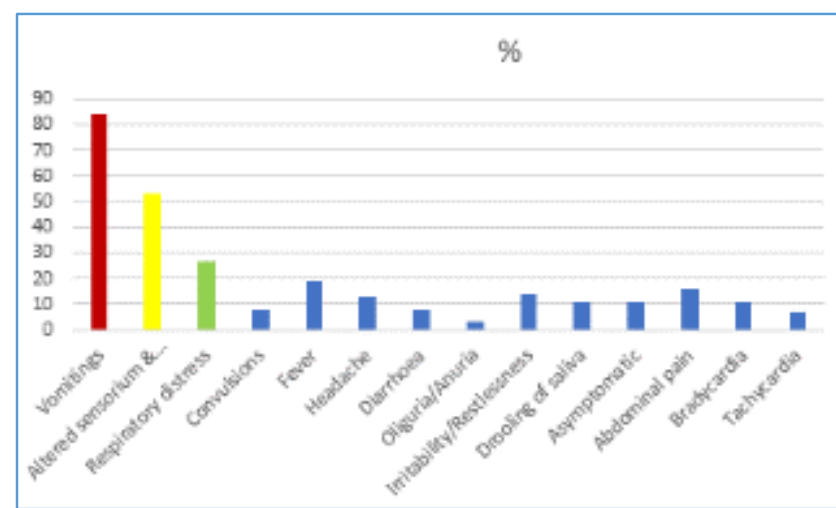

Figure 7. Bar Diagram showing Clinical Symptoms (modes) of Presentation in Acute Poisoning among Hospitalised Children in the Present Study ( $n=117)$

\section{DISCUSSION}

Acute poisoning in children is commonly accidental in nature, with preventable morbidity and mortality. ${ }^{3}$ In the year 2004, more than 45,000 deaths of people under 20 years of age occurred due to poisoning. South-East Asia documented 1.7 fatal child poisoning cases per 100,000 population. 4 Such cases constitute $1-2 \%$ of total paediatric admissions in our country.5,6 The spectrum of poisoning varies considerably from place to place, depending upon age, sex, socioeconomic status and demography. ${ }^{7}$ The range of possible substances that can cause poisoning is vast. Possible toxins include: opioids, cholinergics, narcotics, cocaine, organophosphates, alcohol, atropinics, cyanides, methanol, heroine, carbon monoxide, camphor, boric acid, heavy metals, datura, hydrocarbons, botulinum, acetone, iron, digoxin, clonidine, beta blockers, calcium channel blockers, salicylates, tricyclic antidepressants, theophylline, barbiturates, sedatives, hypnotics, amphetamines, nitrates, nitrites, phenacetin, phenothiazines, arsenic, anticholinergic drugs (such as antihistamines, antidepressants, phenothiazines), anticonvulsants, carbon tetrachloride and plant products such as mushrooms, fava beans, etc. 1,2

Mortality rate depends on the type of compound used, amount ingested, general health of the patient, delay in discovery and transport, insufficiency respiratory management, delay in intubation and failure in weaning off ventilatory support.1,2 Kerosene is the most common hydrocarbon associated with poisoning. 8,9

Datura (anticholinergic alkaloids) the whole plant including its nectar is toxic and intoxication occurs by ingesting the seeds or smoking the plant. In children accidental poisoning may occur due to ingestion of Datura fruits mistaking them for edible fruits. 1,2

In USA, about 203,930 cases of acetaminophen overingestion were reported to US poison centres between 1998 to 1999, making it the leading pharmaceutical agent associated with toxicity.1,10 It is freely available in the market and its use is widely known to general public. Careless approach of the family members towards its use and storage results in high incidence of accidental overdose in children particularly below the age of 6 years, less common but potentially more divesting is the suicide attempt as manipulative episode in the adolescent. Experience with acetaminophen overdoses further indicates a considerable difference between the child under the age of 6 years and adolescent. 10 
Organophosphorus compounds are the most widely used pesticide today (agriculture, industry, the home, gardens and in veterinary practice). Acute pesticide poisoning is an important cause of morbidity and mortality worldwide.11,12 It has been estimated that around three million severe cases of acute pesticide poisoning occur every year with some 220,000 deaths, $95 \%$ of fatal pesticide poisonings occur in developing countries. Children are particularly susceptible to poisoning because of their physiological and behavioural characteristics and are up to 10 times more vulnerable to chemical toxicities than adults because of larger surface area and limited detoxification mechanisms. Most organophosphate poisonings occur in the home and may be secondary to improper storage, illegal chemicals, suicidal or homicidal behaviour. All exposure should be investigated thoroughly to avoid missing cases of abuse or neglect. Potential exposures on children's playgrounds, fields, gardens should be investigated to prevent exposure of other children. ${ }^{11,12}$

Lead poisoning affects both children and adults with children being more susceptible to lead's toxic effects. Lead poisoning can be either acute or chronic. It is usually chronic in childhood due to exposure to inorganic lead over a prolonged period. Because of their normal oral exploratory behaviour, children absorb most of their lead by ingestion. The usual sources of exposure leading to toxicity are lead from paints from walls of old houses either directly ingesting paint chips (pica) or individually by inadvertent ingestion of lead contaminated house dust, food and water stored in lead containers, storage batteries, air borne lead from automobiles and industrial emissions, home remedies and children of lead workers. ${ }^{13}$

Accidental iron ingestion is not uncommon in children, and became a leading cause of unintentional pharmaceutical ingestion fatality. Accidental ingestion of iron is the leading cause of poisoning death in children under six years in United States, despite child resistant packaging since 1986, over 110000 such incidents have been reported leading to 32 deaths, almost $17 \%$ of children deaths reported to poison control centres in USA between 1988-1992, were due to iron poisoning. Though there have been several reports of acute iron poisoning in children in India the exact incidence and mortality is not known either due to scarcity of reports or lack of effective reporting systems. ${ }^{14,15}$

Barbiturate poisoning is specially seen in those children who are on treatment for epilepsy and hence have an easy access to the drug but it is a common poisoning in children. ${ }^{16}$

Corrosives are strong acids or alkalis. Most of these agents are liquids and those at greatest risk are toddlers, the incidence varies from $3-5 \%{ }^{17}$

Naphthalene poisoning occurs mainly in the paediatric age group and the substance is present in a $100 \%$ concentration in naphthalene balls. ${ }^{18}$

As children are particularly susceptible to pesticides, it is imperative to minimise exposures, strict registration should be passed regarding the sale and storage of dangerous chemicals. Paediatricians should work for primary prevention of poisoning by supporting efforts at educating parents about properly storing and disposing toxic substances. Paediatricians can play an important role to prevent poisoning in children by providing anticipatory poison prevention guidance. ${ }^{1}$
Sing et al ${ }^{19}$ studied children up to 15 years and observed the maximum number of acute childhood poisonings occurred above 5 years of age (40.9\%). In Sharma J et al 20 study, maximum number of acute poisoning were found in 11 to 18 years age group. Singhal et al,21 Buch et al 22 and Sharma $\mathrm{U}$ et al ${ }^{23}$ studied acute poisoning in children up to 12 years whereas Kumar et al $^{24}$ studied up to 14 years age group. In our study, about $26.4 \%$ (31 out of 117) of Boys between 1 to 5 years age group and $18.8 \%$ Girls (22 out of 117) between 6 to 10 years age group were affected by acute poisoning. Hence, in the present study, male (boys) preponderance was observed in 1 to 5 years age group and overall female (girls) preponderance i.e. $53 \%, n=117$ was observed in total of all age groups considered. The ratio between Boys: Girls in the present study was 1:1.12, whereas in previous studies reported by Khadgawat et al,25 Niyaj et al ${ }^{22}$ and Ganga et al 26 the ratios were 1.6: 1, 1.25: 1 and 1.7: 1 respectively. Majority of cases were seen from low and middle socioeconomic status (73.5\% and $18.8 \%$ respectively). This was in agreement with previous studies reported by Singh et al, ${ }^{27}$ Barat et $\mathrm{al}^{28}$ and Tak et $\mathrm{al}^{29}$ wherein they reported $98.6 \%, 98 \%$ and $100 \%$ cases in their studies were from low socioeconomic status groups. Singh et al reported that easy availability of some formulations in unacceptable concentration in the local market and lack of education among parents are the reason for higher incidence of childhood poisoning in this socioeconomic group. In the present study, majority of cases belonged to rural and urban slums (47.9\% and $40.2 \%$ respectively) and this finding was in agreement with previous observations made by Kumar V et al and Sharma J et al. The commonest mode of presentation or the commonest symptom found in our study was vomiting (83.8\%) followed by altered sensorium and/or unconsciousness (52.9\%) and respiratory distress $(26.5 \%)$. This finding was similar to that found in many previous studies. Kerosene oil ingestion was the most common poisoning in $29.1 \%$ (34 out of 117) of our study population. Kerosene ingestion was the predominant poisoning in almost all other studies, 19,25,30,31 but in Buch et al study, they found medicines and chemicals as commonest poisoning substances (53\%), and in Sharma J et al study, they found insecticides and pesticides (38.2\%) as commonest poisoning, whereas Kerosene oil poisoning constituted only $4.9 \%$. In the present study, the probable reason for higher incidence of poisoning by Kerosene oil ingestion could be due to more number of affected children from low socioeconomic families and further majority of present study population came from rural and urban slum background where the usage of Kerosene oil as fuel for household cooking purpose is prevalent. In the present study, majority of cases were due to accidental poisoning and 4 cases of 12 years age group had suspected intentional poisoning (2 Kerosene oil ingestion and 2 organophosphate poisoning) and none due to homicidal poisoning. This finding was in agreement with the previous studies as in case of Buch et al, Niyaz et al study and Singh S et al study. 19, 22 American Academy of Paediatrics also identified medicines, cleaning agents and kerosene among common agents implicated in such accidents. ${ }^{32}$ Storage of kerosene/petrol/ diesel in empty bottles of soft drinks within reach of children is often a cause of such poisoning. For preventing poisoning with medicines, previous studies emphasised on keeping them out of reach of the children.2,33 WHO has earlier stressed on laws mandating child-proof 
packaging of medicines. ${ }^{4}$ More importantly, there is gradual rise in the number of medications present in any household at any given point of time, making toddlers vulnerable. ${ }^{34}$ Availability of thyroxine, which is a commonly used drug by adults, in a container probably makes it easier to consume than any other drugs packed in blister packaging or supplied with child-resistant packages.

\section{CONCLUSION}

Accidental ingestion of Kerosene oil was the leading cause of acute poisoning in children in our region. Young children and toddlers especially are innocent and curious in nature and often become victims of accidental poisoning due to their tendency to put things in their mouth. Hence, we recommend Paediatricians to play an important role in preventing this menace by anticipatory guidance to parents during well-child visits and in their routine clinics about the high risk children, careful storage of common toxic household products, as well as drugs implicated in paediatric poisoning and about keeping them in child-proof or locked containers.

\section{REFERENCES}

[1] Chowdhury P, Bagga A, Chugh K, et al. Toxicological emergencies in principles of pediatric and neonatal emergencies. 3rd edn. Jaypee Brothers Medical Publishers 2011;5:457-500.

[2] Osterhoudt KC, Shannon M, Henretig FM. Toxological emergencies. In: Fleisher GR, Ludwig S. eds. Text book of paediatric emergency medicine. $4^{\text {th }}$ edn. Baltimore: Lippincott Williams \& Wilkins 2000:887-942.

[3] Roy MP, Gupta R, Bhatt M, et al. Profile of children hospitalized with acute poisoning in New Delhi. Indian Pediatrics 2017;54(3):246-7.

[4] WHO, UNICEF World Report on child injury prevention. World Health Organization, Geneva, 2008:123-42.

[5] Bhat NK, Dhar M, Ahmad S, et al. Profile of poisoning in children and adolescents at a north Indian tertiary care centre. J Indian Acad Clin Med 2011;13(1):37-42.

[6] Gangal R, Haroon A. Profile of acute poisoning in pediatric age in district Moradabd: a hospital based study. J Indian Acad Forensic Med 2015;37(2):155-9.

[7] Menon RP. Poisonings, injuries and accidents. Ghai Essential Pediatrics. $8^{\text {th }}$ edn. 2013;26:696-702.

[8] Treumper E, De La Rocha SR, Atkinson SD. Clinical characteristics, pathophysiology and management of hydrocarbon ingestion: case report and review of literature. Pediatr Emerg Med 1987;3(3):187-93.

[9] Victoria MS, Nangia BS. Hydrocarbon poisoning: a review. Pediatr Emerg Care 1987;3(3):184-6.

[10] Rumack BH, Mathew H. Acetaminophen poisoning and toxicity. Paediatrics 1975;55(6):871-6.

[11] Fernando F. Pesticide poisoning in the Asia pacific region and the role of regional information network J Toxicol Clin Toxicol 1995;33(6):677-82.

[12] Fenske RA, Kissel JC, Lu C, et al. Biologically based pesticide dose estimates for children in agricultural community. Environ Health Perspect 2000108(6):51520.
[13] Landrigan PJ, Todd AC. Lead poisoning. West J Med 1994;161(2):153-9.

[14] Litovitz T, Manoguerra AS. Comparison of paediatric poisoning hazards. An analysis of 3.8 million exposure incidence. A report from the American Association of Poison Control Centres. Paediatrics 1992;89(6 Pt 1):999-1006.

[15] HHH News. US Department Of Health And Human Services, Food and Drug Administration. 1997:97-103.

[16] Triapthi KD. Sedative hypnotics. In: Essentials of medical pharmacology. $4^{\mathrm{TH}}$ edn. New Delhi: Jaypee Brothers 2001:366-81.

[17] Singh UK, Layland FC, Suman S, et al. Corrosive poisons. Poisoning in children. $2^{\text {nd }}$ edn. 2003:31-9.

[18] Seigel E, Wason S. Mothball toxicity. Pediatr Clin N Am 1986;33(2):369-74.

[19] Singh S, Singhi S, Sood NK, et al. Changing pattern of childhood poisoning. Indian Pediatr 1995;32(3):331-6.

[20] Sharma J, Kaushal RK. Profile of poisoning in children. Pediatric Oncall 2014;11(2):28.

[21] Singhal PK, Kumar H, Rastogi V, et al. Accidental poisoning. Indian Pediatr 1988;25:350-3.

[22] Niyaz BA, Ahmed K, Sethi AS. Poisoning in children. Indian Pediatr 1991;28:521-4.

[23] Sharma U, Saxena S. Accidental poisoning in children in Jaipur (Rajasthan). Indian J Pediatr 1974;41(316): 174-8.

[24] Kumar V. Accidental poisoning in Southwest Maharastra. Indian Pediatr 1991;28:731-5.

[25] Khadgawat R, Garg P, Bansal P, et al. Accidental poisoning. Indian Pediatr 1994;31:1555-7.

[26] Ganga N, Rajarajeswari G. Poisoning in Children. Indian Pediatr 2001;38:208.

[27] Singh M, Hessam MY, Azamy S, et al. Spectrum of poisoning among children in Afghanistan. Indian J Pediatr 1984;51(410):313-6.

[28] Barat D, Sarkar AK. A study of accidental poisoning in children in West Bengal. Indian J Pediatr 1977;44(365):278-83.

[29] Tak SK, Bhandari B, Jain AM, et al. Accidental poisoning in childhood. Indian J Pediatr 1979;46(373):61-5.

[30] Dutta AK, Seth A, Goyal PK, Agarwal V, et al. Poisoning in children, Indian scenario. Indian J Pediatr 1998;65(3):365-70.

[31] Sitaraman S, Sharma U, Saxena S. Accidental poisoning in children. Indian Pediatr 1985;22(10):757-60.

[32] American Academy of Pediatrics. Poison prevention and treatment tips: National Poison Prevention Week. 2016:20-6.

[33] Kohli U, Kuttiat VS, Lodha R, et al. Profile of childhood poisoning patients at a tertiary care centre in north India. Indian J Pediatr 2008;75(8):791-4.

[34] Budnitz DS, Lovegrove MC. The last mile: taking the final steps in preventing pediatric pharmaceutical poisonings. J Pediatr 2012;160(2):190-2. 